\title{
Geo Amapá um aplicativo para o estudo da Geografia amapaense
}

\author{
Ronaldo dos Santos Pantoja ${ }^{1}$, Celiane de Souza Chagas ${ }^{1}$, Cirlene Baia \\ Pereira de Oliveira ${ }^{1}$, Olavo Nylander Brito Neto ${ }^{1}$
}

Grupo de Tecnologias Educacionais - Pós graduação em Informática na Educação Instituto Federal de Educação, Ciência e Tecnologia do Amapá (IFAP) - Campus Macapá, Caixa Postal 68909-398 - Macapá - AP - Brasil

\{ronaldopantoja959, celiane.chagas75, cirlenedo\} @gmail.com, olavo.britodifap.edu.br

\begin{abstract}
This article was based on the development of an application for mobile devices, to be used in the study and research of the geography of Amapá, having in its functionalities the assistive technology for visually impaired people, thus contributing to educational inclusion. It was based on a bibliographical research in which it was searched through the selection and selective, reflexive and analytical reading of books, scientific articles, videos and etc. Obtaining the base material for its construction through App Inventor 2. It was found that it is possible to develop applications to be used in the various areas of knowledge, including the amapaense geographic study, having an inclusive character.
\end{abstract}

Resumo. O presente artigo constituiu-se a partir do desenvolvimento de um aplicativo para dispositivos móveis, a ser usado no estudo e pesquisa da geografia do Amapá, tendo em suas funcionalidades a tecnologia assistiva para pessoas com deficiência visual, contribuindo assim, na inclusão educacional. Baseou-se em uma pesquisa bibliográfica na qual se buscou através da seleção e leitura seletiva, reflexiva e analítica de livros, artigos científicos, vídeos e etc. A obtenção do material base para o sua construção através do App Inventor 2. Constatou-se que é possível desenvolver aplicações para serem utilizadas nas diversas áreas do conhecimento, incluindo o estudo geográfico amapaense, tendo caráter inclusivo.

\section{Introdução}

As novas tecnologias da informação e comunicação (TICs) se apresentam hoje como importantes recursos pedagógicos no âmbito educacional, as razões que justificam essa importância são várias, entre elas estão o surgimento e a evolução do computador, a internet, os aplicativos de dispositivos móveis e outros. Estas tecnologias estão presentes nos diversos setores sociais, entre eles a educação.

Fazemos parte da sociedade da informação que segundo Moran (1999, p.07) nela "todos estamos reaprendendo a conhecer, a comunicar-nos, a ensinar, reaprendendo a integrar o humano e o tecnológico, a integrar o individual, o grupal e o social". A partir da afirmação do autor, podemos dizer que estamos passando por um processo de reaprender a nos conhecer, a nos comunicar e a uma nova maneira de exercer o ensino.

Diante do avanço das TICs e o uso dessas no contexto educacional, vislumbrou-se a criação de um protótipo chamado Geo Amapá, desenvolvido na plataforma App Inventor 2 (MIT, 2019), objetivando disponibilizar aos discentes, docentes e pesquisadores em geral, o acesso de forma simples e dinâmica aos conhecimentos geográficos inerentes ao estado do Amapá, visto que pesquisando nos ambientes tecnológicos, constata-se que há poucos recursos referentes ao conteúdo que se propôs abordar disponibilizados para o ensino e aprendizagem. A Figura 1 mostra o mapa do estado, objeto do estudo. 


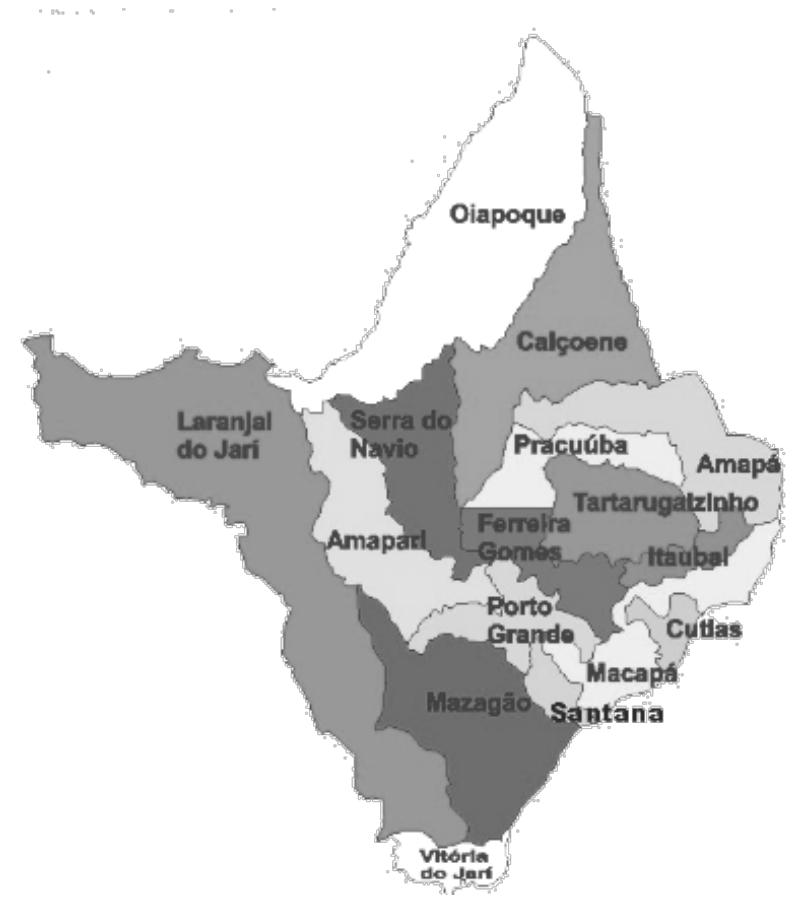

Figura 1 - Mapa do estado do Amapá.

Foram inseridos no aplicativo dados sobre o estado do Amapá, tais como, área, população, economia, limites geográficos, eventos culturais e outros, introduziu-se também a opção de pesquisar através da internet na máquina de busca do Google, além da alternativa de pesquisa em um site específico digitado ou falado pelo usuário, bem como, botões com links para sites favoritos com informações sobre a geografia amapaense.

O estado Amapá, cujos conteúdos fazem parte do Geo Amapá, foi criado em 1988 com a promulgação da atual Constituição Federal, possui uma população estimada conforme o IBGE (2018) de 829.494 habitantes, sua área corresponde a $142.828,521 \mathrm{~km}^{2}$ e sua capital é Macapá.

Outro elemento que compõe o cenário de uso é a tecnologia na promoção da inclusão, pois de acordo com Rezende $(2007$, p. 01$)$ a mesma "tem avançado no sentido de criar meios para que pessoas que possuem determinadas limitações sejam integradas à sociedade de forma menos traumática. Assim, concebe-se a tecnologia como um elemento que pode promover a inclusão".

Além de apresentar dados geográficos da Geografia amapaense, o aplicativo buscou contemplar ainda, a tecnologia assistiva para pessoa com deficiência visual que são recursos tecnológicos criados com o propósito de auxiliar a pessoa com deficiência em suas tarefas diárias, para a pessoa cega pode ser uma aplicação de celular contendo um sensor que identifique os obstáculos e que avise através de um áudio a presença desses, pode ser também "os softwares sintetizadores de voz, os quais permitem ao deficiente visual utilizar o computador.” (BARBOSA; MARTINS; SANTOS, 2013, p. 02).

De acordo com Bersch (2019, p.01) "Tecnologia Assistiva - TA é um termo ainda novo, utilizado para identificar todo o arsenal de recursos e serviços que contribuem para proporcionar ou ampliar habilidades funcionais de pessoas com deficiência e consequentemente promover vida independente e inclusão". Já para Radabaugh (1993, apud BERSCH, 2019, p.01) "para as pessoas sem deficiência a tecnologia torna as coisas mais fáceis já para as pessoas com deficiência, a tecnologia torna as coisas possíveis".

Para Rezende (2007, p.02) "a introdução das tecnologias assistivas /adaptativas no ambiente educacional é algo de extrema relevância, principalmente, como forma de minimizar as barreiras de acesso ao conhecimento, na expectativa de democratizar a informação para as pessoas com deficiência visual”. 
No contexto educacional são inúmeras as dificuldades que o deficiente visual enfrenta, entre essas a realização de uma pesquisa na web através do celular sobre determinado assunto, já que a falta de visão o impede de digitar e mesmo se conseguisse como faria a leitura? Nesse sentido, o recurso reconhecedor de voz supre essa carência, através da consulta, que irá ouvir o assunto a ser pesquisado por meio da pronuncia do usurário, identificando o mesmo e em seguida converte e devolve a resposta em formato de áudio.

O aplicativo apresentado nesse artigo, busca auxiliar a pessoa cega e com baixa visão a pesquisar sobre a geografia dos municípios amapaenses, sendo o mesmo uma tecnologia assistiva que pretende promover a educação inclusiva desse grupo de pessoas com necessidades especiais.

A concepção de Educação Inclusiva é nova no cenário educacional. Em âmbito mundial, esta pauta ganhou força na Declaração de Salamanca (UNESCO, 1994, p.01). Esta propõe que os alunos com necessidades educacionais especiais tenham acesso às escolas de Ensino Regular e que essas instituições devem se adequar a essa nova demanda, pois, "constituem os meios mais capazes para combater as atitudes discriminatórias, construindo uma sociedade inclusiva e atingindo a educação para todos".

No Brasil, na mesma década é aprovada a Lei de Diretrizes e Bases da Educação Nacional (LDBN 9394/ 96), que determina que pessoas com necessidades educacionais especiais sejam incluídas em escolas de Ensino Regular. (BRASIL, 1998). A constituição brasileira de 1988, no artigo 208 já fazia referência ao atendimento de alunos com necessidades especiais, "preferencialmente" em turmas de Ensino Regular.

A pessoa com deficiência visual faz jus a estes direitos, bem como, todos os demais, nesse sentido a educação inclusiva deve alcançar a pessoa cega e com baixa visão, sendo assim, este aplicativo criado pelos autores se propõe contribuir com esse público no âmbito educacional, apresentando funcionalidades que remetem a tecnologia assistiva.

\section{Métodos}

O aplicativo foi desenvolvido na plataforma web MIT App Inventor 2, disponível no site http://ai2.appinventor.mit.edu/, para utilizar a plataforma é necessário acessar o site e fazer o login, utilizando o email e senha do Gmail. A Figura 2 apresenta o ambiente de desenvolvimento da plataforma.

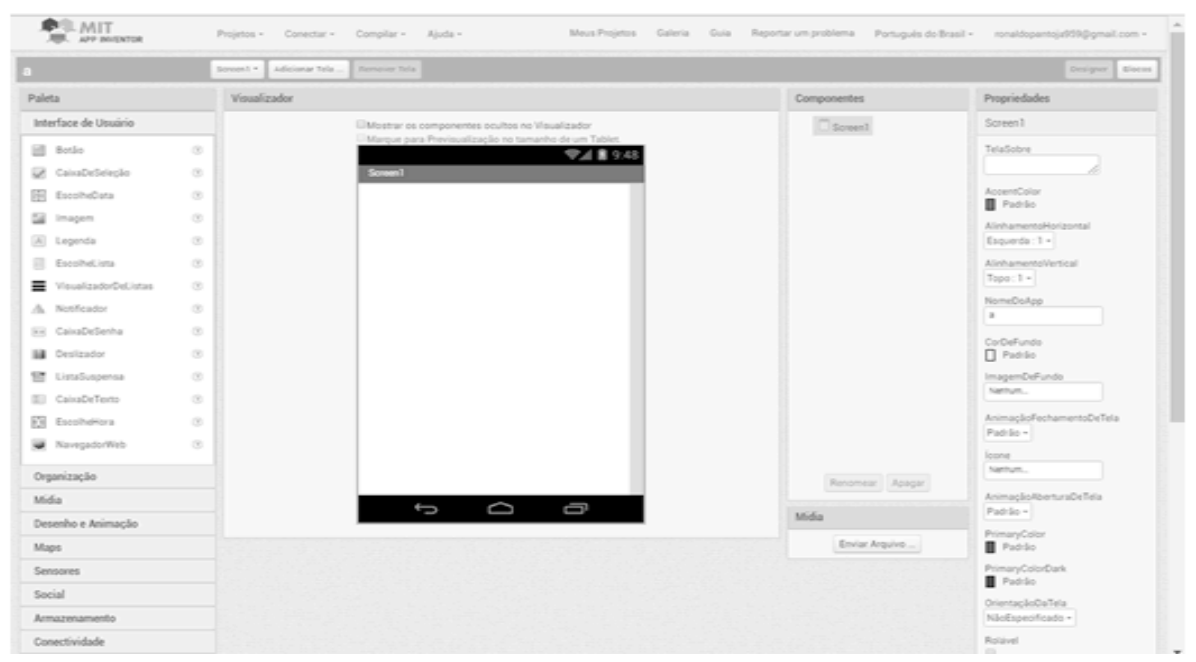

Figura 2 - MIT App Inventor 2.

Utilizou-se como materiais auxiliares para o desenvolvimento do App, sites da internet e a ferramenta Free Screen Vídeo Recorder para corte de imagens que fazem parte do aplicativo, usou-se também o celular da Samsung J prime 2 para gravar os vídeos que compõe o Geo Amapá, empregou-se ainda, a plataforma online-image-editor.com para tirar fundo de imagens. As ferramentas supracitadas são ilustradas na Figura 3. 
VIII Congresso Brasileiro de Informática na Educação (CBIE 2019)

Anais do XXV Workshop de Informática na Escola (WIE 2019)

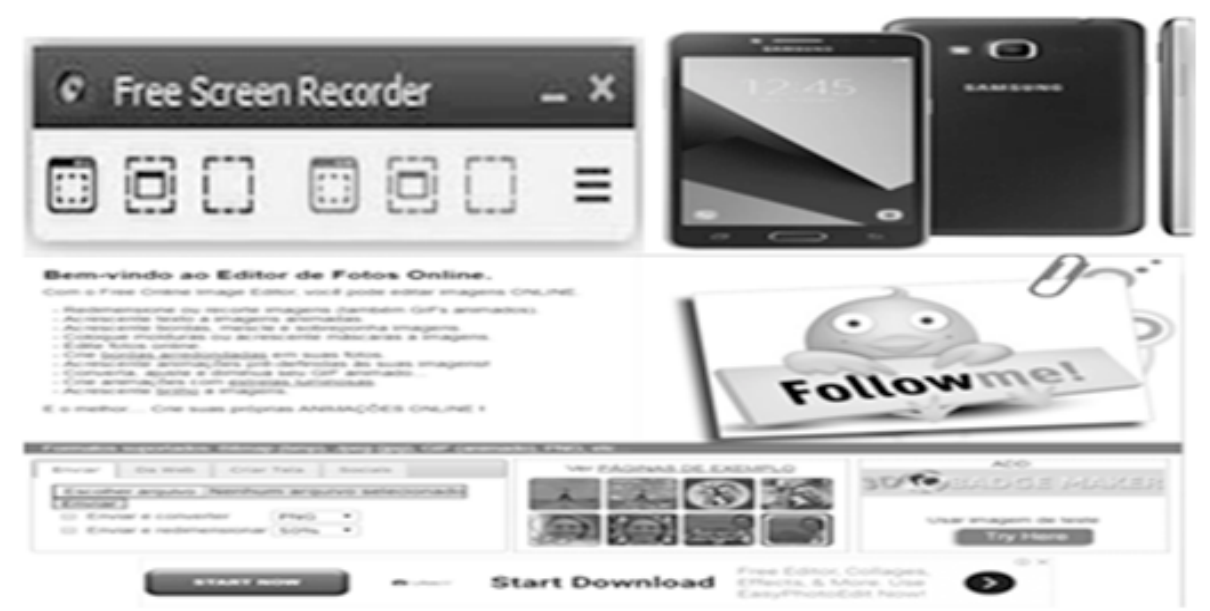

Figura 3 - Free Screen Vídeo Recorder, Samsung J prime 2 e online-image-editor.

O desenvolvimento da aplicação percorreu as quatro etapas abaixo:

Na primeira etapa realizou-se uma pesquisa bibliográfica na qual se buscou através da seleção e leitura seletiva, reflexiva e analítica de livros, artigos científicos, vídeos e outros, a obtenção do material base para o desenvolvimento do aplicativo. Pesquisou-se ainda os conteúdos educacionais a serem inseridos no mesmo, e como tornar-lo uma tecnologia assistiva.

Na segunda etapa construiu-se o projeto e nele se inseriu as telas Screen1, tela2, web e imagens, criando assim a interface gráfica (layout) do App, foi colocado o ícone, os panos de fundos, as imagens, os organizadores, as caixas de textos, os botões, as legendas, os tocadores de áudio, o temporizador, os reconhecedores de voz, o navegador web e realizouse as configurações desses elementos, a Figura 4 ilustra os locais dessas inserções e o ícone do aplicativo.
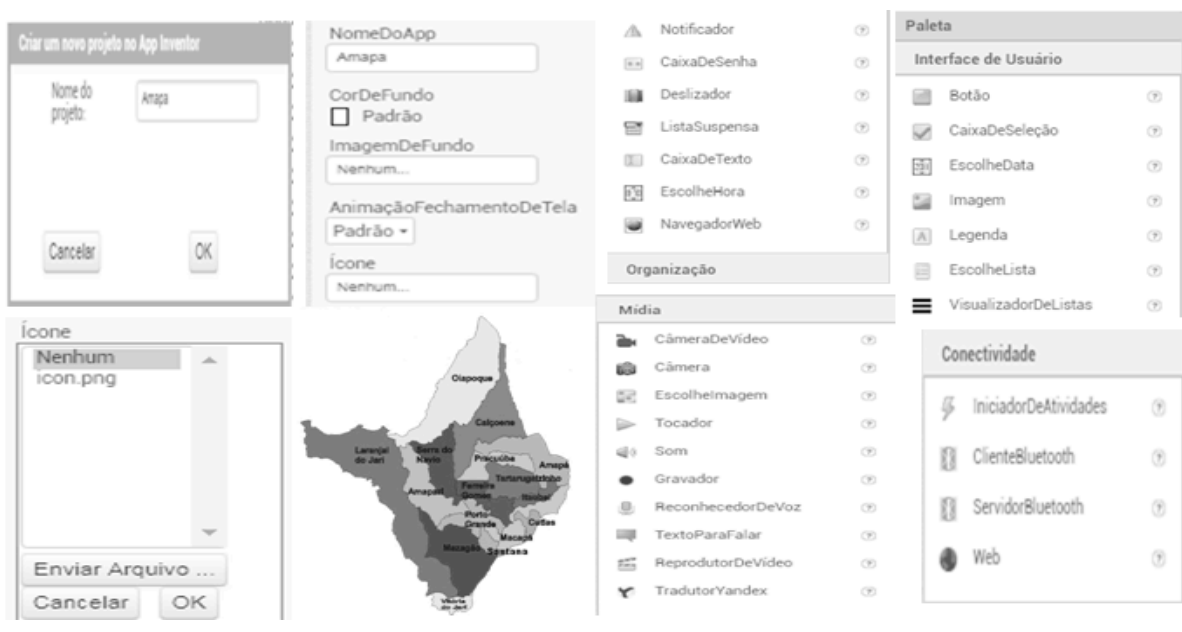

Figura 4 - locais de inserções dos elementos e o icon do aplicativo.

Na terceira etapa foi realizada a construção dos códigos de programação, sendo que a Screen1 é a splash do aplicativo, ao abrir o mesmo permanece por 4 segundos nela e em seguida automaticamente passa para a tela 2 , seu código é mostrado na Figura 5. 
VIII Congresso Brasileiro de Informática na Educação (CBIE 2019)

Anais do XXV Workshop de Informática na Escola (WIE 2019)

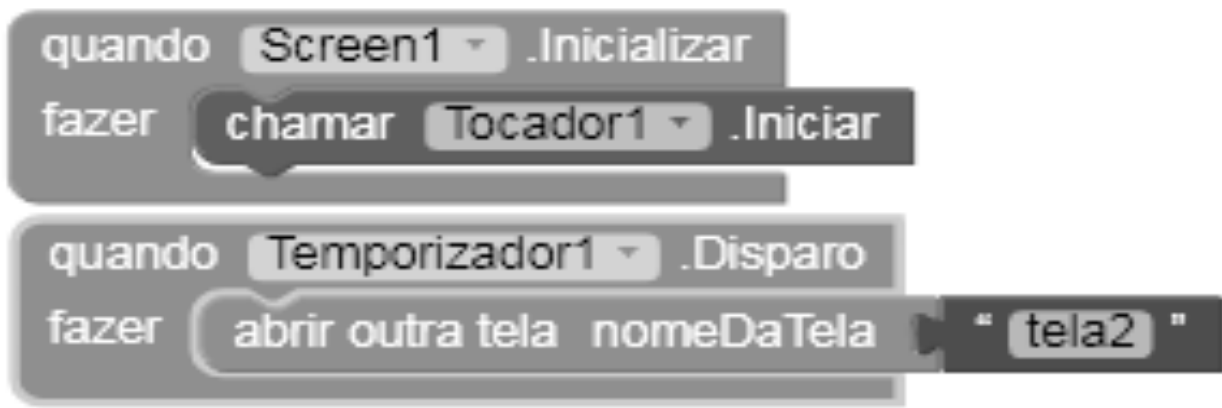

Figura 5 - Código de programação da tela Screen1.

A tela 2 é a tela principal do App, nela estão contidos vários métodos os quais além de chamar as informações inerentes a Geografia do Amapá, chama ainda as telas web e imagens, parte de seu código é ilustrado na Figura 6.

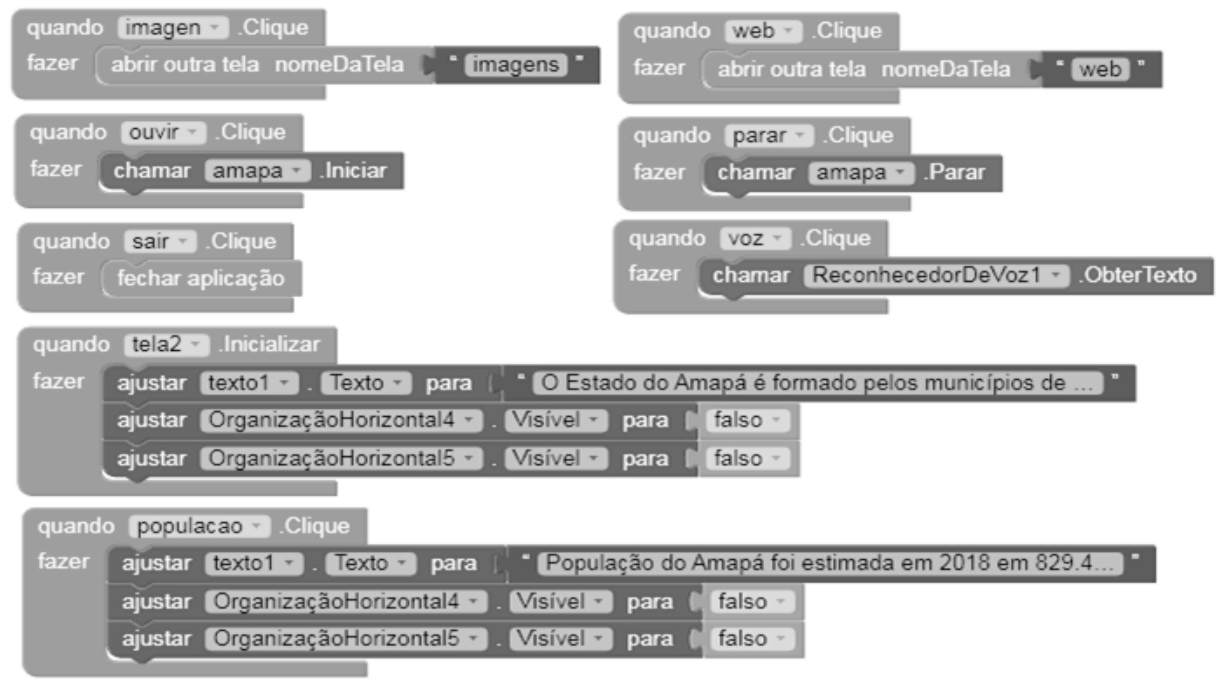

Figura 6 - Parte do código de programação da tela2.

A tela web é o navegador de pesquisa do aplicativo a Figura 7 mostra seu código.

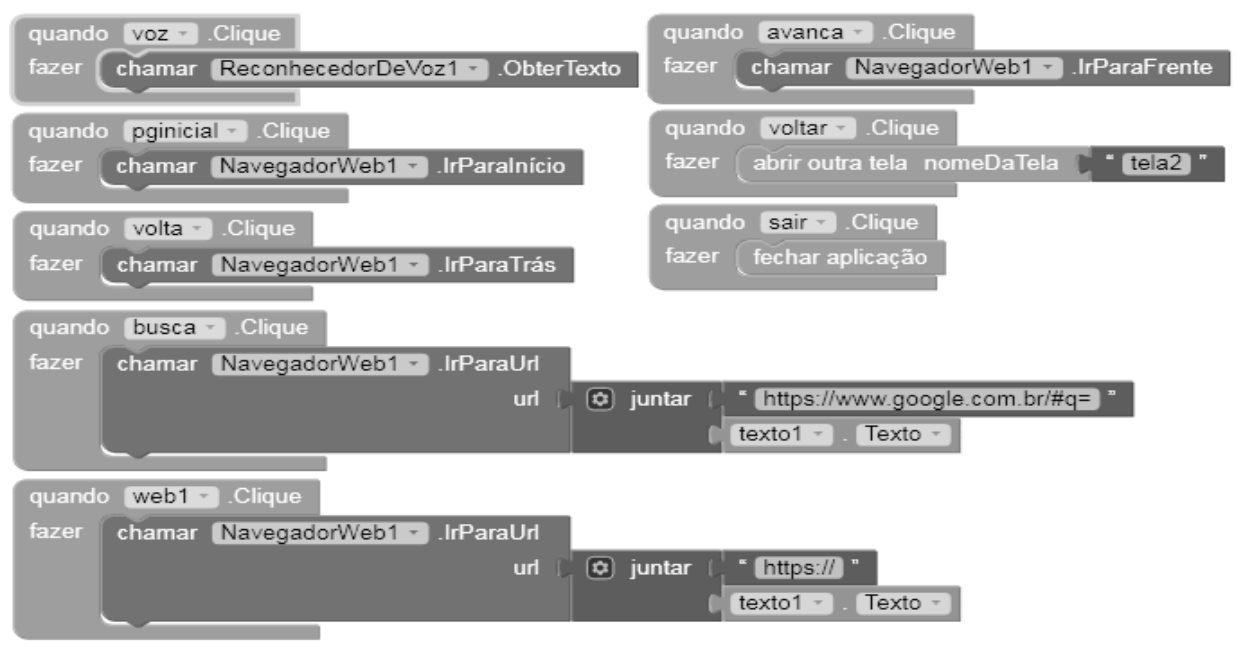

Figura 7 - Parte do código de programação da tela web.

A tela imagens é um slide que visualiza fotos e Figuras do aplicativo. A Figura 8 mostra seu código. 
VIII Congresso Brasileiro de Informática na Educação (CBIE 2019)

Anais do XXV Workshop de Informática na Escola (WIE 2019)

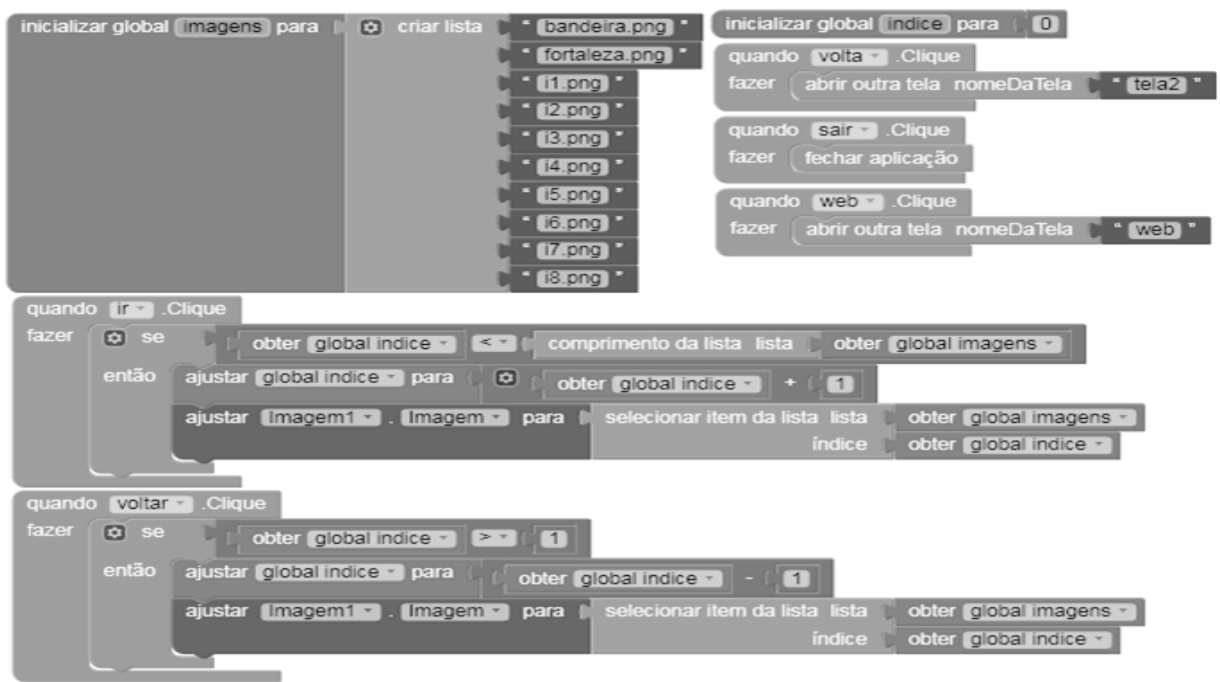

Figura 8 - Parte do código de programação da tela imagens.

Na quarta etapa realizou-se a inserção dos conteúdos sobre Geografia do Amapá, tais como, área, população, economia, limites geográficos, eventos culturais e outros.

\section{Resultados}

O aplicativo apresentado neste artigo denominado Geo Amapá, é uma aplicação para dispositivos móveis com sistema operacional Android, construído na plataforma MIT App inventor 2 , objetivando pesquisar informação relativas a geografia amapaense.

Este aplicativo é composto pelas telas Screen1, tela2, web e imagens. A Screen1 é a splash, tela inicial do App, ao abrir o Geo Amapá e ao ser inicializada a mesma começa a execução do hino do Amapá, após quatro segundos acontece a mudança para tela dois, tela principal. A tela é mostrada na Figura 9.

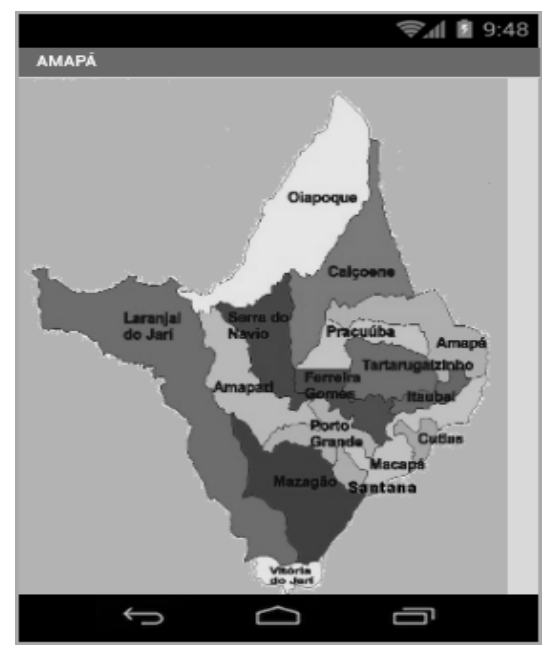

Figura 9 - Splash do aplicativo, escreen1.

A tela 2 contém os principais elementos da aplicação, ao clicar no botão ouvir localizado na parte superior, iniciar-se-á um áudio apresentando o Amapá, clicando em parar finaliza o mesmo, ao tocar no botão voz no centro superior da tela é acionado o reconhecedor de voz para que em seguida o usuário pronuncie o que pretende pesquisar no aplicativo, se o mesmo acioná-lo e pronunciar o vocábulo população, exibir-se-á um texto sobre a população amapaense e executará um áudio narrando o mesmo. O botão web aciona a tela para navegação na internet, já o sair fecha a aplicação.

Ao clicar sobre a imagem do mapa do Amapá, o usuário é direcionado a tela imagens, os botões população, área, limites, economia, hidrografia, cultura e os demais 
VIII Congresso Brasileiro de Informática na Educação (CBIE 2019)

Anais do XXV Workshop de Informática na Escola (WIE 2019)

presentes na tela acionam as informações geográficas as quais fazem menção, sendo que cada item desses podem ser acionados através da função voz para serem ouvidos através de áudios. A Figura 10 mostra a tela2.

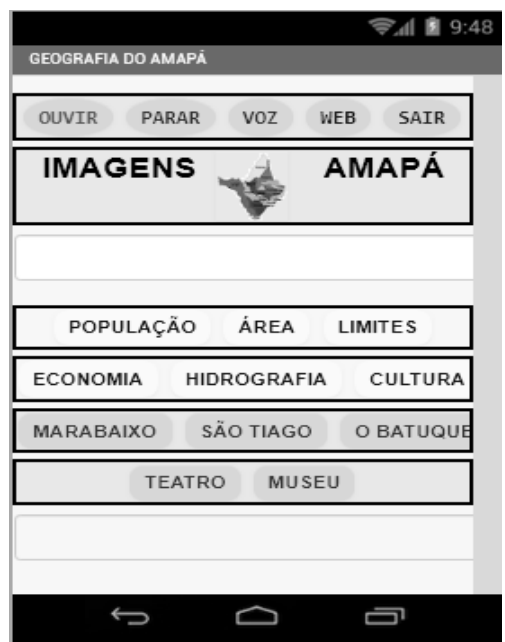

Figura 10 - Tela principal do aplicativo, tela2.

A tela web é o navegador de pesquisa contido no aplicativo, nele é possível realizar pesquisa por assunto específico, por voz acionando o reconhecedor de voz e através de sites favoritos com informações sobre a Geografia amapaense. A Figura 11 apresenta a tela web.

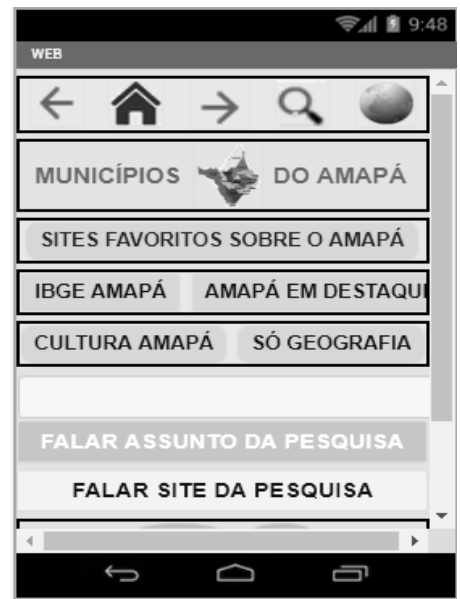

Figura 10 - Tela web.

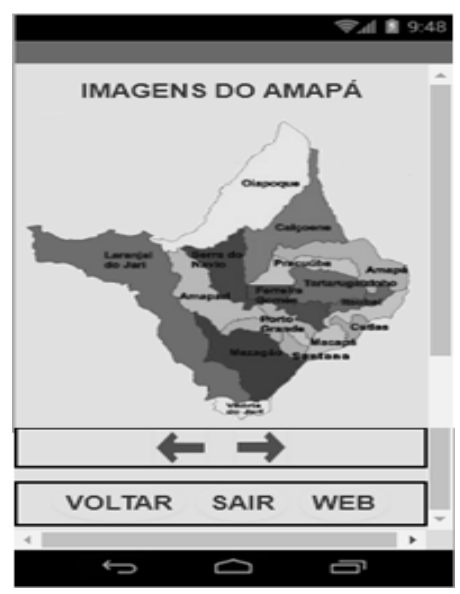

Figura 10 - tela imagens.

A tela imagens é um slide visualizador de fotografias referentes ao estado do Amapá, sendo que os botões das setas possibilitam avançar e voltar às imagens disponíveis, o botão 
VIII Congresso Brasileiro de Informática na Educação (CBIE 2019)

Anais do XXV Workshop de Informática na Escola (WIE 2019)

voltar retorna a tela2, o botão web encaminha a tela do navegador e o sair fecha o aplicativo. A Figura 12 mostra a tela imagens.

Os autores deste trabalho pretendem aplicar o uso da ferramenta em uma pesquisa de campo com alunos do ensino médio de escolas amapaenses, objetivando a validação da mesma.

\section{Conclusão}

Acredita-se que o aplicativo poderá contribuir pedagogicamente no processo do ensino e aprendizagem, visto que o mesmo apresenta potencialidade de proporcionar aos alunos, professores, pesquisadores e usuários em geral desse, a obtenção de informações essenciais para internalização do conhecimento sobre a geografia amapaense, que se apresenta de modo limitado no cenário atual.

Constatou-se que é possível desenvolver aplicações no App Inventor 2, com nível baixo de conhecimento de programação, para serem utilizadas nas diversas áreas do conhecimento, inclusive no estudo da geografia do Amapá e que nesses aplicativos podem estar incluída a tecnologia assistiva, promovendo assim, a inclusão das pessoas com deficiência visual no campo educacional. Pretende-se apresentar a ferramenta em escolas no estado e núcleos de educação especial para difundir o conhecimento da geografia regional, analisando possíveis pontos de melhorias e propagação de conteúdo da ferramenta.

\section{Referências}

BARBOSA, F. A; MARTINS, O. R; SANTOS, M, R. H. Uma Experiência no Ensino de Informática para Deficientes Visuais no Município de Garanhuns-PE, 2013. Disponível em: < http://www.br-ie.org/pub/index.php/wie/article/viewFile/2626/2280>. Acesso em: 15 maio 2019.

BERSCH, R. Tecnologia Assistiva. Disponível em: $<\mathrm{http}$ //www.assistiva.com.br/Introducao_Tecnologia_Assistiva.pdf $>$. Acesso em: 06 mar. 2019.

BRASIL. Constituição (1988). Constituição da República Federativa do Brasil. Brasília, DF: Senado Federal: Centro Gráfico, 2017. 64 p.

. Declaração de Salamanca e linha de ação sobre necessidades educativas especiais.
Brasília:
UNESCO,
1994.
Disponível
em:

http://portal.mec.gov.br/seesp/arquivos/pdf/salamanca.pdf > Acesso em: 06 mar. 2019.

. Ministério da Educação. Lei de Diretrizes e Bases da Educação Nacional. LDB 9.394, de 20 de dezembro de 1996.

IBGE. 2018, Disponível em: < https://cidades.ibge.gov.br/brasil/ap/panorama > Acesso em: 05 mar. 2019.

MIT App Inventor 2. Disponível em: <http://ai2.appinventor.mit.edu/>. Acesso em: 11 fev. 2019.

MORAN, M. J. O Uso das Novas Tecnologias da Informação e da Comunicação na EAD uma leitura crítica dos meios. Disponível em: $<$ http://portal.mec.gov.br/seed/arquivos/pdf/T6\%20TextoMoran.pdf>. Brasília: 1999. Acesso em: 05 mar. 2019.

REZENDE, A. L. A. EASY: Novas Perspectivas na Educação a Distância para o Deficiente Visual, 2007. Disponível em: $<\quad$ http://www.brie.org/pub/index.php/sbie/article/view/553/539 >. Acesso em: 17 maio 2019. 